\title{
Norms and Constraints of Chinese Peasants' Ideology
}

\author{
Li Liu \\ Marxism College of Jilin agricultural University Jilin Changchun, 130118, China
}

Keywords: Peasants; Ideology; Norms; Constraints.

\begin{abstract}
Ideology has undergone a series of changes since it was put forward by the western philosophy. But what is the ideology? At present, there is no systematic and complete concept in the philosophical circles at home and abroad. Under the new historical conditions, there are some outstanding problems that need to be solved urgently in the field of ideology of our country facing complex situations. It is quite urgently necessary to objectively analyze these issues and further explore the reasons for its development and on this basis to scientifically develop appropriate norms and constraints measurements.
\end{abstract}

\section{Introduction}

Ideology is an important category formed with the development of modern western philosophy, which firstly appeared in France in late eighteenth century or early nineteenth century during the period of Napoleon, and the pioneers are the French enlightenment scholar and philosopher Antoine Tracey (or translated as Te Tora West) (Antoine DesttuttdeTracy1754-1836). Tracy put forward the word "ideology" in his four volume book the principle of ideology, which mainly refers to the "concept of science", namely the idea, concept or ideology, and its purpose is to distinguish the ideology with wrong misunderstanding of scholasticism, religion and theology [1]. It subsequently sets off an upsurge of research on ideological issues in western countries. Comprehensively considering the researches of group ideology by foreign scholars and the specific situation of the transforming period in China, the author believes that the group ideology refers to the general term of knowledge shared by the actors within the community. It belongs to a broad ideology, to a certain extent exist correspondingly with the ideology of the state or the mainstream ideology, and its relationship with the main ideology is the relationship of diversity and unity. Its shared knowledge includes knowledge of text and non-text. Text knowledge refers to the knowledge that can be spoken and written, such as values, ideas, theories and so on [2]; non-text knowledge is the knowledge that cannot be spoken or written, such as the "sub consciousness", "feeling", "emotional" and "interest". For the non-text knowledge, British physicist and philosopher Michael Polany had a discussion, "The knowledge people know is much more than what they can express; the statements, logical reasoning, mathematical formula, description composed of words and symbols after all can only be expressed on the basis of the sense of understanding, so the vague and implicit knowledge is more basic than the clear and explicit knowledge."

According to the above analysis, the peasants' ideology is a kind of group ideology. As a kind of collective ideology, it is the social ideology that reflects the social existence of social members in the social class formed by those who have the identity of peasants in the long history of agricultural labor; it is the production of common social status, social experience and social practice in the peasant class. It has the following characteristics: first of all, it depends on and reflect the living conditions of the class, especially the economic and political situation; secondly, its development is unbalanced with the economic and social development; thirdly, it has historical inheritance; fourth, it can be counterproductive to the social existence.

\section{Study on the Origin of Contemporary Chinese Peasants' Ideology}

The rural construction of ideology of our country has made great achievements, the socialist ideology guided the Marxism has been widely recognized by the masses of peasants, and the socialist 
melody is carried forward in the vast rural areas. But at the same time, we must clearly see that the non-mainstream ideology has been gradually spread, interfering and influencing the identity and acceptance of the broad masses of peasants to the socialist ideology to a certain extent. The mainstream ideology construction faces the severe challenges, mainly manifested in the four aspects as shown in Figure 1 [3].

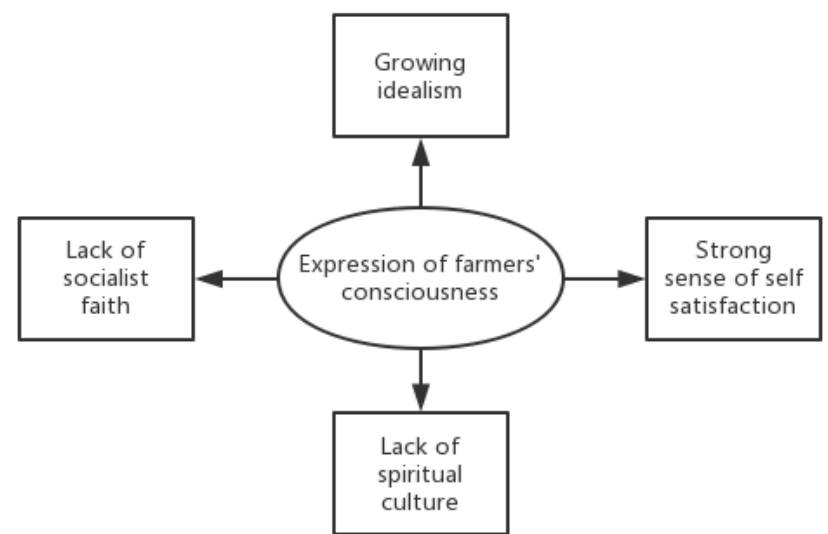

\subsection{Growing Idealism}

Figure 1 Expression of farmers' consciousness

The spreading of theism of idealism directly results in some farmers weakening the scientific belief of Marxism, which is mainly reflected in the issue of religious belief. At present, in many rural areas, religious activities have the trend of being active, but some rural legal religious activity being active, at the same time provides opportunity for the illegal religion and cult organization. As a result, they are under the banner of religion, make use of the disadvantages that the ideological and cultural quality of the farmers is not high to spread rumors, befog the minds of the people, and erode farmers' spiritual world. At the same time, there is a growing trend and a stirring of the activities of feudal superstition. Many superstitious activities, while retaining the traditional forms, put on the cloak of modern science, from covert to open, to achieve the commercialization of the operation and scale effects, with a stronger confusion and temptation.

\subsection{Lack of Socialist Faith}

Some farmers lack firm ideals and beliefs of the cause of socialism with Chinese characteristics, and the mainstream ideology greatly reduces in the rural cohesion and influence. Since the reform and opening up, under the impact of the tide of market economy and the concept of multiculturalism, rural social structure and the peasants' ideas and values orientation has been greatly changed. The utilitarian tendency is gradually emerged among the peasant masses [4]. In addition to the present some grass-roots party organization bureaucracy, serious style of formalism, abuse of power, corruption and degeneration, the bad phenomenon of ignoring the well-being of the masses and various social problems, seriously dampen the enthusiasm of the masses to carry out the production and life, which results conflict emotion of rural social life and peasant psychology on the rural socialist belief, and even leads to some non-socialist or anti-socialist ideas taking advantages, and occupy the position of rural culture.

\subsection{Lack of Spiritual Culture}

The spiritual and cultural life of the masses of farmers is relatively poor, and the popularization and promotion of the scientific spirit in rural areas are subject to inhibition to a certain degree. In the attack of modern pluralistic culture and advanced media technology, the traditional rural cultural entertainment form has gradually disappeared. New cultural and recreational activities adapting to modern rural economic and social development and meeting the aesthetic needs of the masses of peasants is not mature; the rural culture is shrinking, cultural activities platform is widespread absent, and the cultural activities that the peasants spontaneously carry out lack complete security policy and effective organization guidance. 


\subsection{Strong Sense of Self-satisfaction}

Excellent masterpieces of Marx's in rural cultural market is lacked in supply, so farmers' enthusiasm of learning theory is low. For a long time, we pay attention to the prosperity and development of the rural cultural market, at the same time, we ignore the production of Marx doctrine popular books according to psychological characteristics and spiritual needs of the masses of peasants. Currently, the Marx doctrine popular books are basically written by Party Committee Propaganda Department at all levels to rely on the executive power organization, so the language style does not match the farmer's real life [5]. In addition, for a long time, China's rural takes economic work and agricultural production work as the center, at the same time, to a certain extent eases the peasants' ideological and political education work, so theory education and learning have been increasingly weakened and marginalized in rural basic level.

\section{Norms and Constraints of Chinese Peasants' Ideology}

\subsection{Adhere to the Socialist Core Value System to Guide the Construction of Rural Ideology}

Adhere to the socialist core value system to guide the ideological construction of rural areas, enhance the attractiveness and cohesion of the socialist ideology. This is the basic requirement of strengthening the construction of the mainstream ideology in our country at present stage. To really implement this requirement, we should do as the following.

First of all, deeply carry out the learning and education of socialist core value system and take the ideal and belief education as the most essential part for learning and practicing the socialist core value system. Continue to advance the historical process of Marx's Chinization, modernization and popularization, adhere to the principle of "Get close to life and the actual situation of rural farmers" [6], make full use of all the rural culture, adopt various flexible ways, promote the popularization of contemporary Marxism, educate and guide the masses of peasants to use Marx's basic principle, method, the spirit, and dialectical perspective to understand, analyze, and solve practical problems existing and contradictions, enhance the consciousness of socialism, dare to fight against all kinds of wrong ideas, from the deep heart to firm Chinese socialism common ideal, consciously practice the socialist honor and disgrace, and cultivate noble moral sentiment and healthy life. Let the socialist morality really into the consciousness of the farmers, and vigorously create the good vogue of advocating the reality, goodness and beauty and fighting against the negative matters.

Secondly, strengthen the Marxism materialism education, guide farmers to establish a scientific world outlook. Marxism materialism is a powerful weapon against idealism. Adhere to the principle of distinction, classified guidance, actively carry out the propaganda and education of atheism with plans and layers in the rural areas for different regions and different objects, and create a strong opposition atmosphere to the feudal superstition. Through organize and cultivate a high-quality atheistic propaganda team, establish and perfect the mechanism of propaganda work, effectively carry out the spiritual and cultural activities, encourage more farmers really learn, really understand, trust and use Marx's atheism with a loved form.

\subsection{Strengthen the Construction of Basic Level of Party Organizations}

Strengthen the construction of basic level of Party organizations and give full play to the party's leading role in the ideological construction of rural areas. The party's fourth Plenary Session of the 17th CPC Central Committee explicitly pointed out, "We must stick around the central task, service the whole, broaden the field, strengthen the function, further consolidate and strengthen the party's basic level of organizations, make efforts to expand coverage, enhance the vitality of the party organizations to give full play to promote the development, serve the people, unite the people and promote harmony, so the majority of Party members keep the purpose and the masses of peasants in mind." Therefore, in the process of strengthening the construction of rural mainstream ideology, it is necessary to do the following jobs well.

On the one hand, in the ideological focus, improve the consciousness of the Party leading the ideology of the construction of rural areas. Communist Party of China since the beginning of the ruling, takes the socialist ideology construction as its own important tasks and goals, and always 
adhere to the ideology of the Party control. At the new stage of the new period, expecting to continuously push forward the system of rural construction of the mainstream ideology of this complex job, organizations of the Party at all levels and Party members and cadres must stand in the height of consolidating the party's ruling status and ensuring the prosperity of the cause of China characteristics socialist, fully be aware the importance and urgency of strengthening and improving the leading of the Party on the ideological work, and always keep a clear political mind, clarify their responsibility and mission, strengthen ideological consciousness, enhance the consciousness, improve the initiative and systematic tendency of the ideological work, and consolidate the idea foundation of rural ideology construction [7].

On the other hand, promote innovation of the basic level of Party organizations, make efforts to enhance the level and capacity of its leadership ideology construction. Enhance the attraction and cohesion of socialist ideology in the rural areas. It is difficult to achieve good effects by simple theoretical deduction, indoctrination and preaching, we must make the broad masses of peasants' experience real benefits and convenience. Therefore, it is necessary to enhance creativity of work, improve the effectiveness of the work, innovate ideas and methods of work, and care for the farmers suffering and solve the hardship of the masses of peasants, both pay attention to the guidance and education of the ideology of the masses of peasants and solve the practical problems and difficulties of peasants, take effective measures to make the development of modern agriculture, the cultivation of new farmers, the guidance of the masses of peasants to get rich, and the maintenance of rural stability throughout the mainstream ideology construction.

\subsection{Strengthen the Construction of Spiritual Civilization in Rural Areas}

Strengthen the construction of rural spiritual civilization, make the rural cultural market prosperous, actively develop the rural education and science, and vigorously promote the scientific spirit. The construction of socialist spiritual civilization is an important part of the cause of socialist modernization. In view of the current weak reality of Chinese rural spiritual civilization construction, we must attach great importance to ideology, really implement the requirement of grasping together and consolidating the material civilization and spiritual civilization in the specific operation, in the concentrate on economic and social development, strengthen spiritual civilization construction, enrich the spiritual and cultural life of peasants, so as to make the socialist ideology deeply rooted in and softly in the salutary influence of education.

On this issue, one is to resolutely change the previous performance evaluation of leading cadres. That is the wrong approach of taking the GDP growth indicators as the main criteria for the measure of leading cadres [8]. Thoroughly implement scientific outlook on development, improve and perfect the comprehensive, scientific and objective evaluation of the performance of the system, through the establishment of rural spiritual civilization construction linking with the leadership cadres mechanism, strengthen target responsibility system evaluation efforts of rural spiritual civilization construction, implement the spiritual civilization construction of "one vote veto" and other ways, spur and motivate the initiative of leading cadres to pay attention to actively carry out the construction of rural spiritual civilization, so the spiritual civilization construction is always taken as the main line in their mind.

The second is to strengthen the construction of rural cultural facilities and cultural market. Governments at all levels is supposed to increase financial investment, at the same time, they should widely open channels, allow and support through private capital investment, corporate donations, and targeted aid way of helping the city and so on ways to strengthen rural cultural infrastructure construction, deeply implement radio and television coverage, cultural information resources sharing, rural film screenings, farm house and other cultural convenience for peasants, and provide perfect facilities for farmers' spiritual and cultural activities; make the rural cultural market prosperous and developed, pay attention to editing, publishing and market supplying of those Marx doctrine popular book popularized by the masses of peasants, continue to meet the growing cultural needs of the masses of farmers. At the same time, we should strengthen the management and rectification of the cultural market. Cultural market is an important position in the construction of socialist spiritual civilization, and it cannot be a place for the spread of decadent ideology and culture. In particular, it is 
necessary to strictly prohibit the publication of feudal superstition products into the cultural market. Once found, it should severely punish and resolutely crack down the publishers, so as to purify development soil of rural culture.

The third method is to strengthen the training and construction of rural cultural work team. The construction of a cultural work force with comprehensive quality and operational capacity is the foundation and the key to the prosperity and development of rural culture. We must first of all improve the quality of the staffs working for the existing rural culture, and through various forms of in-service education and training, continuously improve the level of business and ability to serve the masses of peasants; and then set up the relevant incentive mechanism, and implement rewards policies of those institutions and workers contribute to the work of the rural cultural construction, attract talents to enter into the local cultural work team, and construct the platform beneficial to individual growth and development; thirdly, it should play the role of a group of folk artists in the activating cultural life and inheriting excellent traditional cultural in folk in rural areas, and truly respect for talent, respect for knowledge, and respect for creation [9].

The fourth is to actively develop the rural education and science popularization work and improve the scientific and cultural quality of farmers. Science and superstition are a pair of natural enemies. History and practice has proved that the development of rural education and science popularization work is an effective way to improve the peasants' scientific and cultural quality and fight against theistic idealism. Only by vigorously developing education and strengthening the science popularization work can it help the farmers to master the scientific and cultural knowledge, establish scientific thinking, learn to use scientific thinking method to understand and transform the world, cultivate new farmers in rural areas, and create a good social atmosphere of "advocating science and eliminating superstition".

\section{Conclusion}

Since the reform and opening up, especially the Sixteen National Congress, great achievements have been made in the construction of socialist ideology in China's rural areas, which has won the high recognition of the masses of farmers. However, there are still a complicated situation in the field of rural ideology, and the construction of the mainstream ideology faces a series of new situations, new problems, and new changes. Based on an overview of the ideology, as well as the existing ideological problems of modern Chinese farmers, the paper puts forward the corresponding norm and constraint measures.

\section{References}

[1] Madsen R. From socialist ideology to cultural heritage: the changing basis of legitimacy in the People's Republic of China [J]. Anthropology \& medicine, 2014, 21(1): 58-70.

[2] Alamgir A K. Race is elsewhere: state-socialist ideology and the racialisation of Vietnamese workers in Czechoslovakia [J]. Race \& Class, 2013, 54(4): 67-85.

[3] Thompson J B. Ideology and modern culture: Critical social theory in the era of mass communication [M]. John Wiley \& Sons, 2013.

[4] Paretskaya A. A Middle Class without Capitalism? Socialist Ideology and Post-Collectivist [J]. Soviet Society in the Era of Late Socialism, 1964-1985, 2012: 43.

[5] Hoberman J M. Sport and political ideology [M]. University of Texas Press, 2014.

[6] Choi S W. The Democratic Peace through an Interaction of Domestic Institutions and Norms Executive Constraints and Rule of Law [J]. Armed Forces \& Society, 2013, 39(2): 255-283.

[7] Elakehal E E. Modelling Self-managing Multi Agent Systems Using Norms [D]. University of Bath, 2015. 
[8] Jahn B. The cultural construction of international relations: the invention of the state of nature [M]. Springer, 2016.

[9] Fuller D Q, Castillo C. Diversification and cultural construction of a crop: the case of glutinous rice and waxy cereals in the food cultures of eastern Asia [J]. The Oxford handbook of the archaeology of food and diet, 2014. 